\title{
LÍMITES Y EVOLUCIÓN DE LOS DERECHOS SOCIALES ¿HACIA SU INDIVIDUALIZACIÓN?
}

\author{
Catalina Ruiz-Rico Ruiz
}

doi: http://dx.doi.org/10.18543/ed-65(1)-2017pp271-299

\begin{abstract}
Sumario: 1. Planteamiento. 2. Derechos sociales: entre la IGUALDAD REAL Y LA DESIGUALDAD FORMAL. 3. LÍMITES DE LOS DERECHOS SOCIALES: DISCRIMINACIÓN Y ARBITRARIEDAD. 4. APLICACIÓN DE LA DISCRIMINACIÓN INDIRECTA A LOS DERECHOS SOCIALES. 5. TENDENCIA A LA INDIVIDUALIZACIÓN DE LOS DERECHOS SOCIALES Y EVOLUCIÓN DEMOCRATIZADORA. 5.1. Argumentaciones jurídicas. 5.2. Tendencia individualizadora en los servicios sociales. 5.3. Evolución democratizadora de los derechos sociales: transparencia y participación.
\end{abstract}

\section{PLANTEAMIENTO}

El desarrollo de la igualdad sustancial a través de los derechos sociales propende, no obstante, al despliegue concatenado de desigualdades formales y reales, con efectos discriminatorios. El riesgo de arbitrariedades subjetivas en el diseño de políticas sociales y leyes aplicables a los derechos sociales, puede generar inmunidad jurídica sin límites o control de constitucionalidad.

Desde esta perspectiva, la transversalidad del principio y derecho de igualdad contribuye a reforzar la exigibilidad y garantías constitucionales de los derechos sociales ${ }^{1}$. En particular, la vulneración del artículo 14 CE mediante

1 AAVV (Dir. Oscar Alzaga), Comentarios a la Constitución española de 1978, (Madrid: 1978), 257 y ss., admite que se trata de un derecho fundamental autónomo, elemento estructural de todo derecho y puede ser un derecho autónomo o transversalizado en derechos fundamentales. 
la confluencia de modalidades discriminatorias (indirecta, múltiple, por circunstancias personales, sociales...) fundamentaliza y confiere una dimensión vinculante a los derechos sociales ${ }^{2}$. Como se analiza en los siguientes epígrafes, la superposición de derechos fundamentales (igualdad, participación...) tiende a maximizar la eficacia jurídica de los derechos sociales ${ }^{3}$.

\section{DERECHOS SOCIALES: ENTRE LA IGUALDAD REAL Y LA DESIGUALDAD FORMAL}

Con carácter general, la presunción tácita de la igualdad formal como derecho a no ser discriminado implica inversamente que la desigualdad formal presenta indicios discriminatorios, aun cuando sus fines sean promover la igualdad real. En esta línea se inscribe la Jurisprudencia constitucional (STC 8/1986 (FJ 4) confirmando que el derecho a la igualdad constituye por imperativo legal un derecho fundamental de la persona a no ser tratada jurídicamente de manera diferente a quienes se encuentran en su misma situación jurídica» ${ }^{4}$.

Sin embargo, a sensu contrario, no se admite en la doctrina constitucional un derecho fundamental a un trato diferente de los sujetos desiguales pese a la posible inefectividad de la igualdad formal y sus consecuencias discriminatorias ${ }^{5}$. En las SSTC 55/1998 de 16 de marzo y 159/1997 (FJ 4) se

${ }^{2}$ Según García Matamoros, «Los derechos sociales desde la perspectiva de los derechos fundamentales», Opinión Jurídica, vol. 3, n. $^{\circ} 6,142$ y ss., los derechos sociales que se «convierten» en fundamentales son aquellos que no siendo denominados como tales en el texto constitucional les es comunicada esta calificación en virtud de la íntima e inescindible relación con otros derechos fundamentales, de forma que si no fueran protegidos en forma inmediata los primeros se ocasionaría la vulneración o amenaza de los segundos.

3 Para Luis María DíEz-PicAzo, Sistema de Derechos Fundamentales, 2013, 199, todos los preceptos constitucionales que proclaman derechos fundamentales recogen a la vez derechos subjetivos.

${ }^{4}$ En esta línea, la doctrina jurisprudencial consolidada sobre derecho de igualdad como las sentencias 8/1981, de 30 de marzo; 10/1981, de 6 de abril; 22/1981, de 2 de julio; 23/1981, de 10 de julio; 49/1982, de 14 de julio; 81/1982, de 21 de diciembre; 34/1984, de 9 de marzo; 166/1986, de 19 de diciembre; 114/1987, de 6 de julio; 116/1987, de 7 de julio; 123/1987, de 15 de julio; 128/1987, de 16 de julio; y 209/1988, de 10 de noviembre, 68/1991, de 8 de abril; 28/1992, de 9 de marzo; 3/1993, de 14 de enero; 147/1995, de 16 de octubre; 46/1999, de 22 de marzo; 39/2002, de 14 de febrero y 87/2009 de 20 abril.

5 Por contra, en favor de la dimensión de derecho fundamental de la igualdad consagrada del artículo 14 se ha pronunciado Antonio CANO MATA, «El principio de igualdad en la Doctrina del Tribunal Constitucional», Revista de Derecho Privado, 1983, cuando indica que: «la igualdad ante la ley configura un derecho subjetivo de los ciudadanos a obtener un trato análogo»; Bustos, «Discriminación por razón de sexo y acciones positivas: Reflexiones a la luz de la jurisprudencia español y aproximación a la ley para la 
aduce que no el art. 14, no ampara la falta de distinción entre supuestos desiguales, esto es, el hipotético derecho a imponer o exigir diferencias de trato. Unicamente se reconoce por la doctrina constitucional, un derecho subjetivo de los ciudadanos a obtener un trato igual, que obliga y limita a los poderes públicos a respetarlo y que exige que los supuestos de hecho iguales sean tratados idénticamente en sus consecuencias jurídicas (STC 154/2006, de 22 de mayo, FJ 6).

En este sentido, Ferrajoli admite que la igualdad, al ser un privilegio normativo, puede resultar inefectiva en diversos grados, como todas las normas, tanto en su dimensión formal como en sus mínimos sustanciales, a causa de las múltiples discriminaciones con las que de hecho puede ser violada mediante lesiones fácticas de los derechos fundamentales. La igualdad jurídica que, al no hacerse cargo de las diferencias y de su concreta relevancia en las relaciones sociales, está destinada a permanecer ampliamente inefectiva y a ser desmentida por las desigualdades concretas en las que de hecho se transmutan las diferencias ${ }^{6}$.

La ineficacia de la igualdad formal procede pues, no sólo de la desatención a las diferencias, sino de su carácter obstaculizador de la igualdad real en base a la discriminación derivada de un trato igualitario de sujetos o categorías en situación desigual. En los derechos sociales se manifiesta particularmente la insuficiencia de la igualdad ante la ley para la consecución de la igualdad real, aunque también puede actuar como impedimento para la consecución de esta última?.

Ahora bien, aunque no se reconoce un derecho a un trato desigual, se protege un derecho a que éste último no provoque discriminaciones, razón por la cual el TC ha venido exigiendo para la admisibilidad del trato desigual una doble garantía basada en la razonabilidad y proporcionalidad al fin perseguido (SSTC 76/1990, de 26 de abril, FJ 9; 214/1994, de 14 de julio, FJ 8; 46/1999, de 22 de marzo, FJ 2; 200/2001, de 4 de octubre, FJ 4; y 39/2002, de 14 de febrero, FJ 4).

igualdad efectiva», Revista de filosofía, Derecho y Política, n. ${ }^{\circ}$ 6, (2007) admite que las diferencias de trato se permiten cuando los supuestos son desiguales y cuando la distinción obedece a un criterio de necesidad y se cumple con ciertos requisitos como la idoneidad y proporcionalidad.

6 Ferrajoli, «Sobre los derechos fundamentales», Cuestiones Constitucionales, n. ${ }^{\circ} 15(2006)$.

7 Vid., AA.VV., Derecho Constitucional III (Madrid: 2014) como presupuestos la constatación de la diferencia o del tratamiento jurídico diferenciador, es decir, que como consecuencia de la medida normativa cuestionada se haya introducido una diferencia de trato entre categorías de personas y la identidad u homogeneidad de los términos de la comparación, esto es, que exista una equiparación lógica, no caprichosa o aleatoria, entre las situaciones subjetivas comparadas. 
La crisis de la igualdad formal transciende a la universalidad propia de los derechos sociales, determinando la necesidad de diferenciación para evitar que un tratamiento uniforme de supuestos que se presentan como semejantes, se convierta en casos de desigualdad material al ignorar la situación real ${ }^{8}$.

La desigualdad formal constituye, desde este prisma, una respuesta antidiscriminatoria por la constitucionalidad de un trato diferenciado a los sujetos en circunstancias desiguales, con aplicación de los parámetros basados en una justificación objetiva y razonable. Conforme a la doctrina constitucional, el principio de igualdad se identifica con la prohibición de toda diferencia de trato que carezca de una justificación objetiva y razonable, vinculando este principio al legislador (igualdad en la ley), a los órganos aplicadores del Derecho (igualdad en la aplicación de la ley) y a los particulares (igualdad horizontal $)^{9}$. La desigualdad formal basada en la uniformidad y homologación de los individuos y grupos se verifica en los derechos sociales sin atención a causas discriminatorias, replanteando el trato igualitario de desiguales sin justificación objetiva y razonable ${ }^{10}$.

Paradójicamente, el alcance de la máxima igualdad real puede requerir dosis de desigualdad formal mediante el descenso a factores o causas discriminatorias, como las circunstancias o necesidades personales, familiares o sociales ${ }^{11}$. La universalidad típica de los derechos sociales como igualdad ante la ley tiende a derivar en un trato igualitario y homogéneo de sujetos desiguales pero el Derecho no tendría que ser igual, sino desigual y por esta razón, puede ser preciso en ocasiones dictar normas aparentemente desigualitarias para favorecer a ciertos sectores de población en situación de inferioridad económica o social ${ }^{12}$.

${ }^{8}$ Vid., E. CARMONA CUENCA, «El principio de igualdad material en la jurisprudencia del Tribunal Constitucional», Revista de Estudios Políticas, n. ${ }^{\circ} 84$ (1994).

9 Para Díez-Picazo, Sistema de derechos fundamentales, 201, la igualdad en el contenido de la ley significa que el legislador no puede dar un trato distinto a personas que se hallen en la misma situación.

${ }^{10}$ Vid., Prieto SANChís, «Los derechos sociales y el principio de igualdad sustancial», Revista del Centro de Estudios Constitucionales, n. ${ }^{\circ} 22$ (1995): 24 y ss., el problema, por tanto, no es si el legislador o el gobierno pueden, sino si deben en algunos casos dar vida a desigualdades jurídicas con el fin de superar desigualdades de hecho; visto desde el lado subjetivo, si cabe defender un derecho fundamental a un tratamiento desigual a partir del art. $14 \mathrm{CE}$.

11 Destaca Jiménez Campo, «La igualdad jurídica como límite frente al legislador», Revista Española de Derecho Político, n. ${ }^{\circ} 9$ (1983): 72, «Lo que prohíbe el principio de igualdad jurídica -se señala en la sentencia de 10 de noviembre de 1981-, es la discriminación (...), es decir, que la desigualdad de tratamiento legal sea injustificada por no ser razonable».

12 Según Carmona Cuenca, El principio... el logro de este objetivo, traducido en el reconocimiento de un derecho desigual igualatorio, permite la adopción de medidas co- 


\section{LÍMITES DE LOS DERECHOS SOCIALES: DISCRIMINACIÓN Y ARBITRARIEDAD}

Los límites de la construcción de derechos y políticas sociales derivan de la inadmisión de resultados contrarios a los derechos y libertades reconocidos en la Constitución (art. 53.1), además de la adecuación al artículo 9.3 CE en cuanto a la vinculación de los poderes públicos, la igualdad real y la interdicción de la arbitrariedad.

En principio, la promoción por los poderes públicos de las condiciones para que la igualdad del individuo y de los grupos en que se integra sean reales y efectivas (artículo 9.2) se traduce a sensu contrario en la inconstitucionalidad de leyes y políticas promotoras de desigualdades. La jurisprudencia constitucional interpreta este precepto como un correctivo del principio de igualdad formal del artículo 14, haciendo hincapié en la necesidad de que el legislador no trate a todos los individuos de la misma manera» sino que sea capaz de tratar de forma diferente aquellas situaciones que son distintas en la vida real. De modo que «lo proclamado en el artículo 9.2 puede exigir un mínimo de desigualdad formal para progresar hacia la consecución de la igualdad sustancial» (Carmona Cuenca).

Pero la exigencia de ciertas dosis jurídicas de desigualdad formal para la promoción de la igualdad real se ajusta a la finalidad del Estado social de Derecho y a los principios rectores de las políticas sociales. En esta línea, la STC 34/1981, de 10 de noviembre (FJ 3), admite que el principio de igualdad jurídica consagrado en el art. 14 hace referencia inicialmente a la universalidad de la ley, pero no prohíbe que el legislador contemple la necesidad o conveniencia de diferenciar situaciones distintas y de darles un tratamiento diverso, que puede incluso venir exigido, en un Estado social y democrático de Derecho, para la efectividad de los valores que la Constitución consagra con el carácter de superiores del Ordenamiento, como son la justicia y la igualdad (art. 1), a cuyo efecto atribuye además a los poderes públicos el que promuevan las condiciones para que la igualdad sea real y efectiva (art. 9.2).

El diseño de derechos sociales implica un tratamiento desigual que debe ser justificado, mientras el trato igualitario de colectivos vulnerables no se somete a control de constitucionalidad ${ }^{13}$. La configuración de derechos sociales puede respetar el principio de igualdad material por destinarse a

\footnotetext{
rrectoras de las situaciones sociales discriminatorias preexistentes para lograr una sustancial y efectiva equiparación todos los sujetos individuales y colectivos de derechos.

${ }_{13}$ Según PrIETO SANChís, Los derechos sociales..., 24 y ss., mientras que la exigencia de una regulación desigual requiere una razón que imponga precisamente el tipo de desigualdad que se pretende establecer, la justificación de un tratamiento igual requiere tan sólo que no logre justificarse la obligatoriedad de la distinción.
} 
categorías de sujetos, aunque si su aplicación deriva en desigualdades entre los mismos se produciría la infracción del artículo 9.2 CE.

La promoción de la igualdad real en aplicación del artículo 9.2 CE con su doble vertiente individual o grupal puede exigir la ruptura de la igualdad formal y también la corrección de las desigualdades materiales generadas. Las políticas y leyes antidiscriminatorias no están exentas de discriminación por la homologación de colectivos sin baremación de sus circunstancias personales y sociales ni atención a un mínimo de casuística social. En este sentido, la STC 3/1983, de 25 de enero (FJ 3) justifica un tratamiento legal distinto en aquellos supuestos en que existe o se supone una desigualdad en las condiciones materiales de los destinatarios de la norma. La quiebra de la igualdad formal responde a las consecuencias discriminatorias derivadas de la indiferenciación de sujetos desiguales, puesto que las medidas y normas tendentes la igualdad material desembocan con frecuencia en nuevas desigualdades. En cumplimiento del artículo $9 \mathrm{CE}$, la atribución y aplicación de derechos sociales justifica tratamientos legales diferenciados para la igualdad real de ciertos sectores, grupos o categorías sociales sin cobertura legal o uniformizados injustificada y desproporcionadamente.

La pretensión de igualdad real de los individuos y de los grupos puede derivar en efectos discriminatorios dentro del campo de las denominadas por Ferrajoli desigualdades antijurídicas ${ }^{14}$. Por esta razón, el trato igualitario en los derechos sociales también debería someterse a un test de constitucionalidad en el supuesto de normas neutras aplicadas a sujetos en situación desigual por su derivación en la esfera de la discriminación indirecta ${ }^{15}$.

Paralelamente, el derecho de igualdad limita las posibles desigualdades irrazonables y discriminatorias, tanto en la fase inicial de atribución de derechos sociales como en su aplicación y ejercicio. Según Garrorena, «el artículo 14 comporta y exige necesariamente en nuestros días una más que cierta apreciación de las premisas materiales y sociales que de modo inexcusable hacen acto de presencia en todo juicio de igualdad» ${ }^{16}$.

Entre los límites también destaca la inadmisión de una arbitrariedad inconsecuente y propensa a efectos de desigualdad, como señala la STC

${ }^{14}$ Como presupuestos, la desigualdad de los supuestos de hecho; finalidad constitucionalmente legítima; congruencia entre el trato desigual, el supuesto de hecho que lo justifica y la finalidad que se persigue; y proporcionalidad entre los elementos anteriores. Una limitación del poder legislativo, que impide que el legislador pueda dictar normas jurídicas introduciendo desigualdades».

15 Según DíEz-PicAzo, Sistema de derechos fundamentales, 196, la igualdad ante la ley provoca desigualdades por vía de la discriminación indirecta.

${ }_{16}$ Para GarRorenA, «Igualdad jurídica e igualdad real y efectiva en la Jurisprudencia del TC», Anales del Derecho, Vol. 6 (1984) el artículo 9.2 debe impregnar de sentido no sólo el principio de igualdad del artículo 14 sino también cualquier otro precepto de la Constitución. 
96/2002 de 25 de abril, de 2002 (FJ 8)... si el Poder legislativo opta por una configuración legal de una determinada materia o sector del ordenamiento no ha de confundirse lo que es arbitrio legítimo con capricho, inconsecuencia o incoherencia, creadores de desigualdad o de distorsión en los efectos legales, ya en lo técnico legislativo, ya en situaciones personales que se crean o estimen permanentes (SSTC 27/1981, de 20 de julio, FJ 10; 66/1985, de 23 de mayo, FJ 1; y 99/1987, de 11 de junio, FJ 4). Para Prieto Sanchís, la valoración conjunta de elementos fácticos y normativos es lo que la jurisprudencia constitucional denomina razonabilidad o interdicción de la arbitrariedad, afirmando que lo igual debe ser tratado igual y lo desigual de modo diferente ${ }^{17}$. Por esta razón, la discriminación entraña siempre una arbitrariedad, o bien, si aun no estableciéndola, carece de toda explicación racional, lo que también evidentemente supondría una arbitrariedad, sin que sea pertinente un análisis a fondo de todas las motivaciones posibles de la norma y de todas sus eventuales consecuencias (SSTC 116/1999, de 17 de junio, FJ 14; y 104/2000, de 13 de abril, FJ 8).

Al margen de estos límites, en la realidad, la configuración legislativa de los derechos sociales presenta una excepcional amplitud amparada en su naturaleza inexigible ${ }^{18}$. La doctrina constitucional reconoce que las diferencias normativas son conformes con la igualdad cuando cabe discernir en ellas una finalidad no contradictoria con la Constitución y cuando, además, las normas de las que la diferencia nace muestran una estructura coherente, en términos de razonable proporcionalidad con el fin así perseguido. Para evitar leyes sociales discriminatorias el principio de igualdad prohíbe al legislador «configurar los supuestos de hecho de la norma de modo tal que se dé trato distinto a personas que, desde todos los puntos de vista legítimamente adoptables, se encuentran en la misma situación o, dicho de otro modo, impidiendo que se otorgue relevancia jurídica a circunstancias que, o bien no pueden ser jamás tomadas en consideración por prohibirlo así expresamente la propia Constitución, o bien no guardan relación alguna con el sentido de la regulación que, al incluirlas, incurre en arbitrariedad y es por eso discriminatoria» (STC 181/2000, de 29 de junio, FJ 10 y STC 144/1988, de 12 de julio, FJ 1).

Tan contraria a la igualdad es, por lo tanto, la norma que diversifica por un mero voluntarismo selectivo como aquella otra que, atendiendo a la

17 Para PRIETO SANChís, Los derechos sociales..., 23, que «C» $\mathrm{y}$ «D» tengan profesiones distintas supone que son parcialmente desiguales, pero no impide que merezcan el mismo tratamiento en ciertos aspectos.

18 Vid., Prieto SAnchís, Los derechos sociales..., 24 y ss., enfocado de este modo, no cabe duda que el principio de igualdad deja abierto un ancho campo de libre configuración legislativa, es decir, un campo donde tratamientos iguales y desiguales resultan simultáneamente lícitos o admisibles. 
consecución de un fin legítimo, configura un supuesto de hecho, o las consecuencias jurídicas que se le imputan, en desproporción patente con aquel fin o sin atención alguna a esa necesaria relación de proporcionalidad (STC 75/1983, de 3 de agosto, FJ 2).

En este sentido, la Jurisprudencia constitucional únicamente se refiere a la adopción de normas especiales que tiendan a corregir los efectos dispares que, en orden al disfrute de bienes garantizados por la Constitución, se sigan de la aplicación de disposiciones generales en una sociedad cuyas desigualdades radicales han sido negativamente valoradas por la propia Norma Fundamental (19/1988, de 16 de febrero, FJ 6). Sin embargo, se precisa una evaluación del impacto de igualdad en términos similares al de género previsto en la Ley Orgánica 3/2007, de 22 de marzo, para la igualdad efectiva de mujeres y hombres (artículo 19), tanto de las políticas públicas, como de las leyes y derechos sociales.

La configuración legal del supuesto de hecho en los derechos sociales presupone un acotamiento de los colectivos o grupos de sujetos vulnerables beneficiarios de los mismos y de las circunstancias o requisitos determinantes de su concesión, mediante una opción discrecional de política legislativa. Al respecto la STC 34/1981, de 10 de noviembre (FJ 3) admite que la apreciación de en qué medida la ley ha de contemplar situaciones distintas que sea procedente diferenciar y tratar desigualmente o, desde otra perspectiva, que no deben ser tratadas igualmente, queda, con carácter general, confiada al legislador. Las medidas adoptadas, que originan la desigualdad, han de estar en función del interés público sin postergar arbitrariamente otros intereses dignos de protección, y dichas medidas han de contar con un fundamento técnico-económico.

Según Ferrajoli, las desigualdades son disparidades entre sujetos producidas por la diversidad de sus derechos patrimoniales reducidas o compensadas por niveles mínimos de igualdad sustancial que están asegurados por la satisfacción de los derechos fundamentales sociales ${ }^{19}$.

Pero el trato diferencial en las políticas sociales para lograr unos objetivos, dificulta la prueba de discriminación en el marco de los derechos sociales. Así resulta de las SSTC 253/2004, de 22 de diciembre y 61/2013, de 14 de marzo, FJ 4 b), requiriendo que los poderes públicos no puedan probar que la norma que dispensa una diferencia de trato responde a una medida de política social, justificada por razones objetivas y ajena a toda discriminación por razón de sexo ${ }^{20}$.

19 Vid., Ferrajoli, «Igualdad y diferencia», Instituto de Investigaciones Jurídicas UNAM, 2015, 12 y ss., es una. La igualdad no es un hecho sino un valor.

20 Además, las SSTJCE de 14 de diciembre de 1995, asunto The Queen v. Secretary of StateforHealth; de 20 de marzo de 2003, asunto Jorgensen, y de 11 de septiembre de 2003, asunto Steinicke). 
La justificación objetiva y razonable de las medidas de política social se facilita en base a su intrínseca finalidad de promoción de la igualdad real y la legitimidad constitucional derivada de su adaptación al artículo 9.3 CE y a los principios rectores. En esta línea, la STC 240/1999, de 20 de diciembre, FJ 6 (y STJUE de 20 de octubre de 2011, asunto Brachner), dispone la constatación de que 'la medida que produce el efecto adverso carece de justificación al no fundarse en una exigencia objetiva e indispensable para la consecución de un objetivo legítimo o no resultar idónea para el logro de tal objetivo' (STC 69/2007, de 16 de abril, FJ 3, o STC 198/1996, de 3 de diciembre, FJ 2).

Desde esta perspectiva, la demostración de inconstitucionalidad y de la posible discriminación derivada de las políticas y derechos sociales se complica por sus fines y objetivos legítimos de igualdad real. La legitimidad de la política social obstaculiza en suma, la prueba de que los derechos sociales y medidas integrados en la misma resultan discriminatorios a consecuencia bien de un trato indebidamente diferenciado o también igualitario de colectivos y grupos desiguales ${ }^{21}$.

La justificación objetiva y razonable de los derechos sociales se incardina en la legitimidad de la política social por sus fines y objetivos de igualdad real. No obstante, el Tribunal Constitucional adiciona a este presupuesto de constitucionalidad que la desigualdad formal y el trato diferenciado no generen discriminación. En particular, la STC 145/1991, de 1 de julio (F. 2) señala que el órgano judicial no puede limitarse a valorar si la diferencia de trato tiene, en abstracto, una justificación objetiva y razonable, sino que debe entrar a analizar, en concreto, si lo que aparece como una diferenciación formalmente razonable no encubre o permite encubrir una discriminación contraria al art. $14 \mathrm{CE}^{22}$.

Por consiguiente, dentro de los límites expuestos, la desigualdad formal resulta difícilmente impugnable desde una perspectiva constitucional salvo si

${ }^{21}$ En conclusión, de acreditarse los dos primeros presupuestos, el Tribunal debe analizar si la medida controvertida responde a una finalidad legítima de la política social del Estado miembro, es adecuada para alcanzar el objetivo perseguido y no se excede de lo que es necesario a tal fin, sin olvidar que el análisis de la jurisprudencia del Tribunal de Justicia de la Unión Europea reconoce la existencia de discriminación indirecta cuando la aplicación de una medida nacional, aunque formulada de manera neutra, perjudique de hecho a un número mucho mayor de mujeres que de hombres (SSTJUE, Brachner C-123/10 EU: C 2011: 675 ap. 56 y Elbal Moreno, C-385/11, EU: C 2012: 746 ap. 29).

22 Para ello deberá atender necesariamente a los datos revelados por la estadística (STC 128/1987, de 14 de julio) y en este mismo sentido se ha manifestado el Tribunal de Justicia de las Comunidades Europeas en Sentencia de 9 de febrero de 1999. 
la homogeneización y uniformidad legal de los desiguales provoca efectos discriminatorios ${ }^{23}$.

\section{APLICACIÓN DE LA DISCRIMINACIÓN INDIRECTA A LOS DERECHOS SOCIALES}

La posibilidad de derechos sociales discriminatorios no desaparece por el hecho de integrar políticas sociales justificadas, objetivas y razonables, considerando que la vulneración del derecho fundamental de igualdad se produce mediante la neutralidad normativa y la confluencia de factores discriminatorios. En concreto, la discriminación indirecta o múltiple puede operar como denominador común en los derechos sociales por su imprevisión en las políticas sociales ${ }^{24}$.

Particularmente, la discriminación indirecta se presenta como una modalidad discriminatoria atípica sin consecuencias jurídicas en el ordenamiento español, salvo por razón de género, permaneciendo como laguna en el derecho nacional pese a sus efectos adversos ${ }^{25}$.

La traslación del concepto de discriminación indirecta a colectivos o sectores en situación de desventaja en virtud de disposiciones, criterios o prácticas aparentemente neutros, resulta verosímil a nivel jurídico y con una base jurisprudencial a través de sentencias como la del Tribunal Superior de Justicia de Cantabria, de 14 de noviembre de 2005 (FJ 2), al referirse a «toda disposición normativa heterónoma, cláusula convencional o contractual, pacto individual o decisión unilateral que, aparentemente neutra, ocasione una desventaja particular a una persona respecto de otras por las referidas razones, siempre que objetivamente no respondan a una finalidad legítima y que los medios para su consecución no sean adecuados y necesarios».

${ }^{23}$ Sobre los límites a derechos sociales, vid., PRIETO SANCHÍs, Los derechos sociales..., 23. En el marco de una Constitución como la española, que el Estado puede dar vida a desigualdades normativas con el fin de alcanzar igualdad de hecho es algo que está fuera de toda duda, aunque, por supuesto, no es una competencia absoluta, sino limitada, entre otras cosas por el propio principio de igualdad jurídica. El art. 9.2 CE, dice el Tribunal Constitucional, permite «regulaciones cuya desigualdad formal se justifica en la promoción de la igualdad material».

${ }^{24}$ La Directiva 2000/43/CE, de 29 de junio, sobre la aplicación del principio de igualdad de trato de las personas independientemente de su origen racial o étnico (artículo 2.2), y la Directiva 2000/78 CE, de 27 de noviembre.

${ }_{25}$ El artículo 2.1 b) de la Directiva 2006/54/CEE, de 5 de julio, para la aplicación del principio de igualdad de oportunidades e igualdad de trato entre hombres y mujeres en asuntos de empleo y ocupación, define la discriminación indirecta por razón de sexo como «la situación en que una disposición, criterio o práctica aparentemente neutros sitúan a personas de un sexo determinado en desventaja particular con respecto a personas del otro sexo. 
Los efectos colaterales discriminatorios de las normativas asépticas y aparentemente neutras son connaturales a las leyes sin transversalidad de la igualdad como derecho. Las normativas destinadas a la corrección de desigualdades tienden a provocar consecuencias discriminatorias por su generalidad y universalidad, sin diversificación ni baremación entre sujetos vulnerables. El predominio de la igualdad formal en las disposiciones amortiguadoras de las desigualdades materiales posibilita que su aplicación genere agravios comparativos e incluso, discriminación indirecta.

En los derechos sociales, esta modalidad discriminatoria apenas adquiere protagonismo salvo en relación al tratamiento neutral que provoca efectos perjudiciales a un sexo respecto de otro, reduciéndose su tipicidad al ámbito de la igualdad de género. Así la STC 145/1991, de 1 de julio, FJ 2) asevera que «cuando ante un órgano judicial se invoque una diferencia de trato ... y tal invocación se realice precisamente por una persona perteneciente al colectivo tradicionalmente castigado por esa discriminación -en este caso las mujeres-, el órgano judicial no puede limitarse a valorar si la diferencia de trato tiene, en abstracto, una justificación objetiva y razonable, sino que debe entrar a analizar, en concreto, si lo que aparece como una diferenciación formalmente razonable no encubre o permite encubrir una discriminación contraria al art. $14 \mathrm{CE}$ ».

Por otra parte, la atención legislativa a la discriminación indirecta en el campo de los derechos sociales podría actuar a modo de instrumento preventivo y sustitutivo de acciones positivas, como medidas compensatorias de desigualdades de ciertos colectivos. La prevención de la discriminación indirecta en la atribución de derechos sociales requiere una atención superior a criterios y circunstancias individuales, personales y sociales, reduciendo la necesidad de acciones positivas enfocadas a la igualdad real de los colectivos ${ }^{26}$.

La modulación de la fuerza normativa de la ley o derechos según grupos personales (Jiménez Campo) basada en una justificación objetiva, razonable y en la proporcionalidad del caso concreto, su orientación a los principios rectores (SSTC 95/2000, de 10 de abril, FJ 5 y 19/1982, de 5 de mayo, FJ 6) y la adecuación al logro de los valores, bienes y derechos constitucionales (STC 82/1990, de 4 de mayo, FJ 2, 126/1994, de 25 de abril, FJ 5), previenen y evitan la discriminación indirecta ${ }^{27}$.

${ }_{26}$ Para «Carbonell, Igualdad y Constitución», Cuadernos de la Igualdad, n. ${ }^{\circ}$ 1, (2004), para quien ejemplo de este tipo de medidas son las becas, la progresividad del impuesto sobre la renta, los descuentos en el acceso a servicios públicos, los beneficios en prestaciones públicas...

27 Según Bustos BotTaI, «Discriminación por razón de sexo y acciones positivas». (Comunicación presentada en el Seminario Los Derechos Humanos, la utopía de los ex- 
Aunque la traslación de esta modalidad discriminatoria al campo de los derechos sociales resulta complicada no sólo por su atipicidad legal en este campo sino por su intrínseca finalidad de promoción de la igualdad material. El trato diferenciado justificado por la legitimidad de las políticas sociales impide un replanteamiento de su constitucionalidad en base a la igualdad formal entre colectivos discriminados.

La configuración legal de derechos sociales a favor de unos destinatarios específicos exige la razonabilidad de la diferencia subjetiva para justificar la excepcionalidad. La diversificación respecto del régimen jurídico general que introducen los derechos sociales requiere una justificación objetiva y razonable del tratamiento diferenciado para la protección de los colectivos vulnerables, adecuada a los bienes constitucionalmente protegidos y a los principios rectores de políticas sociales. En suma, la concesión discrecional de los derechos sociales aun siendo facultativa por los poderes públicos, no puede ser arbitraria sino razonable y proporcional entre las medidas, resultados y finalidad que persiguen ${ }^{28}$.

En este sentido, la discriminación indirecta en el campo de los derechos sociales no se adapta a la denominada «discriminación por indiscriminación» (Jiménez Campo), considerando que esta última sólo tendrían relevancia jurídica a partir del artículo 14 de la CE cuando entre los destinatarios de la norma se incluyan sujetos que no cuenten en absoluto, entre sus condiciones personales, con el elemento o elementos al que lógicamente deben ligarse las consecuencias jurídicas imputadas, a partir de una interpretación teleológica de la norma ${ }^{29}$. No obstante, podría enlazar con la discriminación por omisión en derechos sociales excluyentes de colectivos o grupos de sujetos vulnerables sin justificación ni proporcionalidad derivada de la discrecionalidad del legislador. Al respecto, la exclusión de una categoría personal del ámbito de aplicación de una norma puede, aun sin considerarse válida en cuanto tal diferenciación, resultar irreparable por vía jurisdiccional, al no

cluidos, mayo de 2007 en la Universidad Carlos III de Madrid.), 7, el TC sentaba la doctrina de que las violaciones al principio de igualdad se producen cuando «la desigualdad del tratamiento legal sea injustificada por no ser razonable», lo que tendría que evaluarse en cada caso concreto considerando el cumplimiento del principio de proporcionalidad en la diferenciación; Jiménez Campos, La igualdad jurídica como límite frente al legislador, Revista Española de Derecho Político, n. ${ }^{\circ}$ 9, 1983.

${ }^{28}$ La STC 61/2013, de 14 de marzo de 2013 (BOE n. ${ }^{\circ}$ 86, de 10 de abril de 2013) confirma «como regla general, el principio de igualdad exige que a iguales supuestos de hecho se apliquen iguales consecuencias jurídicas y, en consecuencia, veda la utilización de elementos de diferenciación que quepa calificar de arbitrarios o carentes de una justificación razonable».

${ }_{29}$ Así, JimÉnEz CAMPos, «La igualdad jurídica como límite frente al legislador», $R e$ vista Española de Derecho Político, n. ${ }^{\circ} 9$ (1983). 
ser posible que el Tribunal extienda, sin mayores matices, la regulación antes negada a los casos afectados. En tales supuestos, la declaración consiguiente del Tribunal sí podría dar lugar, en tanto no se colme por el legislador el vacio normativo considera ilegítimo, a una situación de «inconstitucionalidad por omisión», de problemático control jurisdiccional en todo caso (Jiménez Campos).

El Tribunal Constitucional considera exclusivamente como presupuestos de la diferencia de trato la necesidad de una justificación objetiva y razonable y que no encubra una discriminación contraria al artículo $14 \mathrm{CE}$, pero sólo a propósito de la discriminación de género. El problema radica en la aplicación y extensión de esta doctrina jurisprudencial a las discriminaciones derivadas de la diferencia de trato a los derechos sociales y por otras causas discriminatorias como las circunstancias personales o sociales. Para Cascajo la Corte Constitucional ha puesto de relieve que si bien tratándose de opciones de política social y económica se confía a la discrecionalidad del legislador, no renuncia a sentar los posibles criterios de constitucionalidad de las leyes de ejecución de derechos sociales, es decir, de controlar las formas y modos propios del uso de la discrecionalidad legislativa ${ }^{30}$.

La demostración de la discriminación indirecta requiere una evaluación del impacto de igualdad de las leyes tras un periodo razonable de aplicación y según estadísticas, consideradas por el TC como un medio revelador de su existencia (SSTC, 128/1.987, de 14 de Julio y 253/2004, de 22 de Diciembre, FJ 4). Aunque se exceptúa en esta modalidad discriminatoria la aportación de un término de comparación, como la existencia de un trato más beneficioso, siendo suficiente que una norma o interpretación produzca efectos desfavorables para un grupo (STC 253/2004, de 22 de diciembre, FJ 5) ${ }^{31}$.

En la actualidad sólo se ha desarrollado a nivel legal y jurisprudencial la discriminación indirecta por razón de sexo permaneciendo sin base jurídica esta modalidad discriminatoria por otras causas sospechosas de discriminación $^{32}$. La desatención a las circunstancias personales, familiares o sociales

${ }^{30}$ Destaca Cascajo Castro, «Derechos sociales», Cuadernos de Derecho Público, n. ${ }^{\circ} 37,19$.

${ }^{31}$ Como dispone el Tribunal de Justicia de las Comunidades Europeas es suficiente que exista una norma o una interpretación o aplicación de la misma que produzca efectos desfavorables para un grupo formado mayoritariamente, aunque no necesariamente de forma exclusiva, por trabajadoras femeninas.(trabajadores a tiempo parcial-STJCE de 27 de junio de 1990-, trabajadores con menos de dos años de permanencia en su puesto de trabajo -STJCE de 9 de febrero de 1999-, trabajadores con menos fuerza física -STC 149/1991-, etc.).

32 En esta línea, STJUE de junio de 1990, asunto Kowalska; de 7 de febrero de 1991, asunto Nimz; de 4 de junio de 1992, asunto Bötel; o de 9 de febrero de 1999, asunto Seymour-Smith y Laura Pérez), «es jurisprudencia reiterada del Tribunal de Justicia que el 
en base a criterios rígidos de renta o estratificaciones legales puede provocar un trato discriminatorio indirecto de los beneficiarios de derechos sociales.

Ahora bien, las políticas y derechos sociales discriminatorios vertebrados en torno a la igualdad de sujetos o grupos vulnerables en situación desigual derivan en la confluencia de discriminaciones. Así se confirma por la STC 13/2001, de 29 de enero 2001 (FJ 8) admitiendo que la prohibición de discriminación consagrada en el art. $14 \mathrm{CE}$ comprende no sólo la discriminación patente, es decir, el tratamiento jurídico manifiesta e injustificadamente diferenciado y desfavorable de unas personas respecto a otras, sino también la encubierta, esto es, aquel tratamiento formal o aparentemente neutro o no discriminatorio del que se deriva, por las diversas circunstancias de hecho concurrentes en el caso, un impacto adverso sobre la persona objeto de la práctica o conducta constitucionalmente censurable en cuanto la medida que produce el efecto adverso carece de justificación (no se funda en una exigencia objetiva e indispensable para la consecución de un objetivo legítimo) o no resulta idónea para el logro de tal objetivo.

La discriminación indirecta en la configuración y aplicación de los derechos sociales puede implicar simultáneamente discriminación múltiple por adicionar una nueva discriminación a colectivos previamente discriminados. La identificación de colectivos beneficiarios de las políticas y derechos sociales penetra en el terreno de la discriminación indirecta por su homogeneización injustificada y también por obviar otras causas discriminatorias mediante un tratamiento igualitario e indiferenciado de grupos o sujetos con diverso nivel de vulnerabilidad ${ }^{33}$.

La discriminación indirecta por causas diversas de género y la discriminación múltiple presentan una atipicidad que genera desprotección jurídica de los sujetos y colectivos discriminados, integrando una modalidad discriminatoria por omisión que se superpone a ambas causas ${ }^{34}$. Esta ausencia de

Derecho comunitario se opone a la aplicación de una medida nacional que, aunque esté formulada de manera neutra, perjudique a un porcentaje muy superior de mujeres que de hombres, a menos que la medida controvertida esté justificada por factores objetivos ajenos a cualquier discriminación por razón de sexo».

33 Al respecto, vid., BARRERÉ/MORONDO TARAMUNDI, «Subordiscriminación y Discriminación interseccional: Elementos para una Teoría de Derecho Antidiscriminatorio», Anales de la Cátedra Francisco Suárez, n. ${ }^{\circ} 45$ (2011), un proceso injusto de identificación de una clase o categoría específica, bien a través de la intencionalidad discriminatoria que la identifique, bien mediante la demostración de las desventajas de todos los miembros de esa categoría.

${ }^{34}$ Para Diamond Ashiagbor, Reto de la discriminación múltiple e intersectorial en la ley de la UE (University of London ADC, tomo LXVI, 2013, fasc. I), 298, es cierto que se hace referencia a la combinación concreta de diferentes motivos de discriminación que darían lugar a la discriminación múltiple de lo cual deducimos la importancia que el legis- 
regulación obliga a acciones positivas en países como España donde el ordenamiento jurídico no establece la posibilidad de que la discriminación pueda estar basada en más de un motivo a la vez.

Como consecuencia de la imprevisión legal de ambas modalidades discriminatorias, no se dispone un régimen coercitivo y sancionador con indemnizaciones, daño moral o garantías de indemnidad ${ }^{35}$. Pero la indiferencia de los poderes públicos hacia sujetos multidiscriminados, generalmente mujeres con discriminación acumulativa, implica una revictimización o victimización secundaria, prohibida por Tratados Internacionales.

En principio, la gravedad de la discriminación múltiple por sus efectos nocivos, debería conllevar una agravación de la sanción o indemnización, especialmente si procede del mismo causante ${ }^{36}$. La discriminación por varios factores o causas concurrentes multiplica el daño y agrava la conducta del pluridiscriminador. Un informe por encargo de la Comisión europea en 2006 a un grupo de expertos en derecho a la igualdad ultimado en julio de 2009 bajo el título, Multiple discrimination in EU Law. Oportunities for legal responses to intersectional gender discrimination, aborda el estudio de soluciones legales para la lucha de la discriminación de mujeres basada en más de una causa. De nuevo se demuestra que la UE era consciente de que, en el fenómeno de la multidiscriminación, el factor mujer está mayoritariamente presente ${ }^{37}$. Como conclusión más inmediata, el referido informe pone de manifiesto que existen personas que sufren discriminación por razón de diversas causas, generando

lador da a esta figura máxime cuando, como se ha dicho, ya la Exposición de Motivos de la LOI hace referencia expresa a la discriminación múltiple.

${ }^{35}$ La Directiva 2010/41/UE del Parlamento Europeo y del Consejo de 7 de julio de 2010 sobre la aplicación del principio de igualdad de trato entre hombres y mujeres que ejercen una actividad autónoma (DOUE de 15 de julio de 2010, L 180/1) do a priori».

${ }^{36}$ El artículo 25.1 del Proyecto de Ley integral para la igualdad de trato y no discriminación establecía: «La persona que cause discriminación por alguno de los motivos previstos en el apartado primero del artículo dos de esta Ley (lista abierta de motivos de discriminación) responderá del daño causado. Acreditada la discriminación se presumirá la existencia de daño moral». Por tanto, el daño moral se presume cuando se ha demostrado la existencia de discriminación. Siendo la discriminación múltiple, dicho perjuicio moral, será con toda probabilidad, mayor. Tradicionalmente, en los sistemas continentales el régimen de responsabilidad ha cumplido una función principalmente de reparación o compensación y solo secundariamente de prevención 98.

37 Vid., SERRA CRISTÓBAL, «La discriminación múltiple en los ordenamientos jurídicos español y europeo», Revista Española de Ciencia Política, n. ${ }^{\circ}$ 31, Marzo 2013, p. 170 , admitiendo que para el grupo de expertos, es necesario ese impulso normativo comunitario que, a su vez, incentivaría políticas nacionales en el mismo sentido. Es más, algunos de ellos recurrieron al principio de subsidiariedad para defender que el mejor modo de alcanzar mayores logros en política discriminatoria es la regulación de ésta desde el ámbito supranacional. 
un mayor efecto de exclusión en ellas, lo que supone un punto de partida para nuevas políticas comunitarias de discriminación.

La discriminación indirecta múltiple tiende a convertirse en sistémica dentro del marco de las políticas y derechos sociales por su actual estadio de universalidad, y además obviar cualquier pretensión de profundizar en las desigualdades internas entre los grupos y colectivos previamente seleccionados como beneficiarios, sea por circunstancias personales, familiares o socia$\operatorname{les}^{38}$. La interseccionalidad de factores, móviles y causas discriminatorias no suele reflejarse en la configuración política y legal de los derechos sociales, sin que los poderes públicos asuman íntegramente una auténtica promoción de la igualdad real ${ }^{39}$.

En particular, la confluencia de determinadas causas discriminatorias previstas en el artículo $14 \mathrm{CE}$ como racismo, género, circunstancias personales o sociales puede derivar en discriminación indirecta y múltiple si no se prevén legalmente ${ }^{40}$. El revisionismo de las políticas discriminatorias y la articulación de garantías procedimentales acordes con la discriminación múltiple se abordan en la Resolución de 2 de abril de 2009, sobre Propuesta de Directiva relativa al principio de igualdad de trato entre las personas independientemente de su religión o convicciones, discapacidad, edad y orientación sexual. A través de diversas enmiendas concluyó que «los procedimientos jurídicos nacionales deben garantizar que un demandante pueda exponer todos los aspectos de una demanda por discriminación múltiple en un único procedimiento» (enmienda 23).

Desde una perspectiva jurisprudencial, se introduce directa o indirectamente una diferencia de trato entre grupos o categorías de personas (STC

38 A propósito, vid., REY MARTíNEZ, «La discriminación múltiple, una realidad antigua, un concepto nuevo», Revista Española de Derecho Constitucional, n. ${ }^{\circ}$ 84, (2008): 272 , considerando que los poderes públicos españoles no sólo pueden, sino que deben empezar a adoptar este enfoque múltiple de la discriminación para identificar grupos sociales vulnerables que pueden calificarse como minorías dentro de otras minorías.

39 Vid., COll-PlanAs, Cruell, «La puesta en práctica de la interseccionalidad política: el caso de las políticas LGTB en Cataluña The Implementation of Political Intersectionalityfor LGBT Policies in Catalonia», Revista Española de Ciencia Politica, n. ${ }^{\circ} 31$, (2013), 156, se asume que las personas que agrupa en su seno no están solamente definidas por su identidad de género y sexualidad sino que en la configuración de su posición socia intervienen otros factores, como la edad, la raza o la clase social.

${ }^{40}$ Según el TC, en este recurso de amparo no se alega trato discriminatorio por circunstancias personales o sociales (subjetivas) del art. 14 C.E, sino en una desigualdad fundada en elementos objetivos, que es la contemplada por el art. 31.1 C.E, con referencia al principio de capacidad económica. La STC 36/1999 de 22/03/1999 habrá vulneración del art. 14 C.E. por la Ley Tributaria únicamente «cuando arbitrariamente se establezcan discriminaciones entre contribuyentes entre los cuales no media ninguna razón objetiva de diferenciación» (ATC 230/1984, FJ 1 y 2). 
181/2000, de 29 de junio, FJ 10) siendo indispensable además que las consecuencias jurídicas que resultan de tal distinción sean adecuadas y proporcionadas a dicho fin, de manera que la relación entre la medida adoptada, el resultado que se produce y el fin pretendido por el legislador superen un juicio de proporcionalidad en sede constitucional, evitando resultados especialmente gravosos o desmedidos (STC 253/2004 de 22/12/2004). También las situaciones subjetivas comparables deben ser homogéneas o equiparables, es decir, que el término de comparación no resulte arbitrario o caprichoso (SSTC 148/1986, de 25 de noviembre, FJ 6; 29/1987, de 6 de marzo, FJ 5; 1/2001, de 15 de enero, FJ 3), sin que el tratamiento desigual pueda producir consecuencias jurídicas desproporcionadas a la finalidad perseguida, para evitar resultados excesivamente gravosos o desmedidos (SSTC 27/2004, de 4 de marzo, FJ 3, y 104/2004, de 28 de junio, FJ 4).

La diferencia de trato puede presentar en apariencia una justificación objetiva y razonable encubriendo una discriminación por homologar o uniformar categorías de sujetos que deben ser tratados desigualmente entre sí; y como indicio discriminatorio los tribunales atienden necesariamente a los datos revelados por la estadística (STC 128/1987, de 14 de julio, FJ 6, Sentencia TJUE de 9 de febrero de 1999).

En la práctica, las políticas y leyes sociales no deberían optar por un tratamiento legal igual con abstracción de cualquier elemento diferenciador de relevancia jurídica (154/2006 de 22 de mayo de 2006, FJ 8), y de la posible confluencia de factores discriminatorios. Sin embargo, se adopta la regla de que el criterio de diferenciación empleado ha de atender a los casos ordinarios y más frecuentes y no a los casos particulares, pues la generalidad de la norma puede ser una garantía de la seguridad jurídica y de la igualdad; por lo que el juicio de igualdad debe realizarse teniendo en cuenta los criterios legales establecidos para la distinción y no los supuestos particulares individualizados (STC 16/1994, FJ 5).

En consecuencia, la tendencia permanente a la igualdad formal posibilita la inversión de las leyes y políticas sociales antidiscriminatorias en discriminatorias, reflejando que la transversalidad de la igualdad debe ceder para transversalizar la desigualdad ${ }^{41}$. La tendencia a la categorización e incluso a

${ }^{41}$ Según SERra, La discriminación múltiple ..., la realidad exige una visión más transversal de la igualdad, no sólo en el sentido de ver cómo las políticas de igualdad deben impregnar todas las políticas y todas las esferas de la sociedad, sino también en observar cómo de modo transversal u horizontal concurren varias causas de discriminación en una persona o colectivo. La confluencia de múltiples factores discriminatorios o las circunstancias personales, familiares o sociales de los sujetos discriminados impide un tratamiento indiferenciado de los mismos... O de atender a las especificidades que acompañan a los casos de discriminaciones aditivas. 
la individualización de las políticas y derechos sociales prevendría la discriminación indirecta y múltiple aunque pueda parecer un retroceso en el principio de igualdad ante la 1 ey ${ }^{42}$. Desde este prisma, el principio de igualdad como límite a la legislación social debe incluir la desigualdad objetiva, razonable o proporcionada y un tratamiento desigual ${ }^{43}$. Para garantizar la igualdad resulta necesario un ordenamiento jurídico altamente diferenciado como exige una sociedad con una compleja tipología de desigualdades entre ciudadanos, individuos y grupos ${ }^{44}$.

\section{TENDENCIA A LA INDIVIDUALIZACIÓN DE LOS DERECHOS SOCIALES Y EVOLUCIÓN DEMOCRATIZADORA}

\subsection{Argumentaciones jurídicas}

Las desigualdades entre titulares de derechos sociales no pueden ser indiferentes al legislador sin incurrir en el riesgo de discriminación indirecta y múltiple ${ }^{45}$. No obstante, el trato jurídico diferenciado en los derechos sociales

${ }^{42}$ La legislación antidiscriminatoria tiende a ser selectiva y a detectar actitudes reiteradas de prejuicios que, en muchas ocasiones, están profundamente arraigadas en la sociedad. Esas actitudes pueden reiterarse en diferentes países del mundo, incluso en varios países de Europa o dentro de un mismo Estado, pero buscar una solución universal a los problemas de la discriminación puede ser un error. De igual modo que decíamos que la respuesta a cada uno de los supuestos de discriminación interseccional ha de recibir una respuesta ad hoc por parte de los poderes públicos.

${ }^{43}$ Vid., Pérez Portilla, Principio de igualdad: Alcance y perspectivas, (México: 2005), 87 y 93 y ss., sobre el principio de igualdad como límite a la legislación, aseverando que el principio de igualdad no implica rigurosa uniformidad de tratamiento en la regulación legal, ya que, si así fuera, en ocasiones podría llegarse a resultados absurdos. Dentro del principio de igualdad tienen cabida diferenciaciones de tratamiento, aunque no la pura y simple diferenciación de tratamiento.

44 Al respecto, vid., PÉrez Portilla, Principio de igualdad..., 99, para quien todas estas afirmaciones confirman que la mera forma de regulación general y abstracta y de la aplicación igual de la ley, no son garantía suficiente de la igualdad. Ésta requiere además unas exigencias en la selección por el legislador de los criterios de diferenciación, dada la imposibilidad de otorgar el mismo tratamiento a todas las personas y dada la necesidad correlativa de proceder mediante distinciones normativas en un orden jurídico tan altamente diferenciado como el que la compleja sociedad actual exige. Se comprueba así que la igualdad se inserta en una especie de concepto de admisión o rechazo de las desigualdades de trato, al tiempo que se aleja de la idea de una paridad estricta ante la ley. Así, se trata de limitar el poder soberano del legislador, limitando su discrecionalidad al exigirle una justificación de la diferenciación del tratamiento jurídico entre sujetos.

${ }_{45}$ Vid., Monereo ATIENZA, «Herramientas para una teoría de los derechos sociales», Anuario Filosofía del Derecho, n. ${ }^{\circ} 22$, (2005): 270 y ss. los derechos sociales son principalmente derechos de igualdad Doscientos setenta y dos dad no garantiza la igualdad en 
para eludir la discriminación indirecta o múltiple colisiona con el criterio de universalidad intrínseco a sus fines de integración social ${ }^{46}$. Los fines inclusivos y solidarios inherentes a los derechos sociales impiden considerar la discriminación encubierta bajo la idea de universalidad ${ }^{47}$.

La selección subjetiva de titulares de derechos sociales no suele replantearse ni sujetarse a un control o escrutinio de constitucionalidad por discriminación, pese al riesgo de inconstitucionalidad y la ausencia de evaluación del impacto discriminatorio ${ }^{48}$. El acotamiento subjetivo de los derechos sociales no se fiscaliza desde una perspectiva constitucional en base a su carácter concesional, a modo de donación unilateral de los poderes públi$\cos ^{49}$. Si bien el reforzamiento constitucional de la asignación subjetiva de derechos sociales permitiría a su vez constitucionalizar la deselección y la regresividad por ausencia de motivación constitucional y aplicación de la doctrina de los actos propios a los poderes públicos ${ }^{50}$. El proceso

los resultados, es decir, que partiendo de posiciones iguales se tengan los mismo efectos, ya que siempre hay circunstancias no legales (riqueza, azar, etc.) que pervierten esa igualdad inicial. Así, se debe interpretar la igualdad material como igualdad en los resultados o igualdad en el punto de llegada, que será consecuencia del conjunto de medidas a tomar por los poderes públicos para lograr una semejante calidad de vida.

46 Destaca Liborio Herrera, «Estado, Constitución y Derechos sociales», Revista de Derecho del Estado, n. ${ }^{\circ}$ 5, (2003): 85, la idea de integración social toma la forma de universalidad...la universalización de la necesidad par a la integración social, se inscribe en la lógica de la integración social.

47 Vid., Liborio Herrera, Estado, Constitución..., 88, sobre la doctrina que defiende la universalidad de derechos a través de categoría de solidaridad.

${ }^{48} \mathrm{Al}$ respecto, NIKKEN, «La protección de los derechos humanos: haciendo efectiva la progresividad de los derechos económicos, sociales y culturales», Revista IIDH, Vol. 52, 123, Es igualmente inexacto que todas las personas estén en condiciones de absoluta igualdad frente a los derechos civiles y políticos. Por una parte, hay numerosas disposiciones y medios de protección específicos para atender la situación especial de personas o grupos de personas especialmente vulnerables, que son tratadas de una manera hasta cierto punto selectiva. Por tanto, los criterios de distinción fundados en razones de temporalidad, de materia o de persona no resisten un escrutinio detenido y aparecen como criterios rígidos enderezados a establecer una diferenciación preconcebida.

49 Vid., Liborio Herrera, Estado, Constitución ..., la capacidad del Tribunal Constitucional para controlar el desarrollo legislativo de los derechos sociales sólo alcanza a controlar si la legislación se sitúa por debajo de un mínimo constitucionalmente inadmisible. Pero sería importante tener en cuenta que la capacidad de un Tribunal Constitucional para controlar si la legislación implementa adecuadamente los derechos a protección, organización y procedimiento tampoco alcanza más allá de un mínimo constitucionalmente inadmisible.

50 Para NiKken, La protección de..., 32 y 123, una vez configurados los derecho sociales no pueden ser discriminatorio y sobre la insuficiencia de la universalidad de los derechos sociales. 
especificador para determinación de los sujetos titulares de derechos puede ser discriminatorio por regresivo y también arbitrario sino han cambiado las circunstancias ni el supuesto de hecho ${ }^{51}$. La introducción de desigualdades normativas pese a gozar en origen de una fundamentación constitucional puede provocar desviaciones, y se hallan permanentemente expuestas a que su pretensión de igualdad material genere desigualdades aplicativas sin causa o justificación objetiva o razonable ${ }^{52}$. Según Prieto Sanchís, debe admitirse como constitucional que trato distinto que recaiga sobre supuestos de hecho que fueran desiguales en su propia naturaleza, cuando su función contribuya al restablecimiento de la igualdad real a través de su diferente régimen jurídico crear igualdad de hecho tiene que aceptar desigualdades de iure... dado que el logro de la igualdad real consiste precisamente en operar diferenciaciones de tratamiento normativo a fin de compensar por vía jurídica una previa desigualdad fáctica. La exclusión indebida de colectivos, el agravio comparativo entre sujetos vulnerables, o la desatención a circunstancias personales o familiares pueden plantear la constitucionalidad de los derechos sociales concedidos ${ }^{53}$.

Sin embargo, la aportación de un tertium comparationis capaz de quebrar la convicción de que varios sujetos han de ser tratados de modo igual, puede basarse en circunstancias personales o familiares, sociales ${ }^{54}$. La introducción de desigualdades normativas fundamentada en origen puede, no obstante, degenerar en un trato igualitario discriminatorio en el seno del grupo seleccionado como destinatario de los derechos subjetivos, si genera desigualdades injustificadas ${ }^{55}$.

51 Vid., Prieto Sanchís, Los derechos sociales..., 22, se observa aquí lo que Bobbio ha llamado un proceso de especificación, «consistente en el paso gradual, pero siempre muy acentuado, hacia una ulterior determinación de los sujetos titulares de los derechos.

${ }^{52}$ Según Prieto Sanchís, Los derechos sociales..., 22, todos los derechos prestacionales son expresiones concretas de la igualdad sustancial, pues consisten en un dar o en unhacer en favor de algunos individuos según ciertos criterios que introducen inevitablemente desigualdades normativas.

${ }^{53}$ PRIETO SAnchís, Los derechos sociales...por ejemplo, si el Estado decide que un cierto grupo de niños obtenga educación gratuita atendiendo a su renta familiar, el juicio de igualdad de ture no necesita plantearse si con tal medida se limita la desigualdad entre niños pobres y ricos, sino sólo si han quedado indebidamente excluidos algunos niños.

${ }^{54}$ Para PRIETO SANChís, Los derechos sociales..., 23, toda igualdad es siempre, por eso, relativa, pues sólo en relación con un determinado tertium comparattonis puede ser afirmada o negada», y la fijación de ese tertium «es una decisión libre, aunque no arbitraria, de quien juzga, y afirmar que dos sujetos merecen el mismo trato supone valorar una característica común.

55 Para Prieto SAnchís, 24 y ss., Si no me equivoco, esta valoración conjunta de elementos fácticos y normativos es lo que la jurisprudencia constitucional denomina razonabilidad o interdicción de la arbitrariedad: ü existe discriminación cuando «la desigual- 
La individualización o categorización máxima en el reconocimiento derechos sociales como mecanismo antidiscriminatorio, implicaría una reversión de la igualdad formal en términos próximos a las leyes ad personam ${ }^{56}$. Pero la desigualdad formal y material entre colectivos vulnerables y discriminados no puede considerarse inconstitucional siempre que se adapte a los presupuestos de la Jurisprudencia constitucional. En particular, la diferenciación normativa no está prohibida siempre que haya fundamento aunque debe superar la presunción de que la igualdad formal no es discriminatoria y la carga de demostración de su carácter justificado en los casos en que el factor diferencial, es precisamente uno de los típicos que el artículo14 concreta» (STC 81/82, de 21 de diciembre).

La traslación de la igualdad formal a los derechos sociales se traduce en una abstracción de la delimitación de sus titulares contraviniendo el artículo $14 \mathrm{CE}$ por falta de contextualización en relación a sus circunstancias discriminatorias ${ }^{57}$. Pero la universalidad inherente a la construcción teórica de los derechos sociales no puede justificar suficientemente la homogeneización y uniformidad de colectivos en situación desigual.

A la integración social como fundamento del trato diferenciado en este tipo de políticas y derechos se suma la imposibilidad económica de su reconocimiento universal. Sin embargo, la igualdad formal en el marco de los derechos sociales incrementa su coste económico por el trato igualitario de titulares con una diversidad de circunstancias discriminatorias que podrían

dad del tratamiento legal sea injustificada por no ser razonable»54; para que exista violación del principio de igualdad es preciso que el tratamiento desigual «esté desprovisto de una justificación objetiva y razonable»; el principio de igualdad exige «que las consecuencias jurídicas que se derivan de supuestos de hechos iguales sean, asimismo, iguales, debiendo considerarse iguales dos supuestos de hecho cuando el elemento diferenciador introducido por el legislador carece de relevancia para el fin perseguido en la norma.

56 Vid., JiMÉNEZ CAMPOS, La igualdad jurídica..., cit., de la absoluta prohibición de leyes ad personam y que ha llegado posteriormente, a reconocer la existencia irreprochable de disposiciones de este tipo. También el Tribunal Constitucional italiano, por su parte, en sentencias como la número 80, de 14 de abril de 1969, ha admitido la posibilidad jurídica de tales normas (20). A la postre, la prohibición del privilegio que fundamentaba la desconfianza frente a la ley singular puede quedar razonablemente atendida, aunque con un control de otro tipo, a través de la interdicción de la discriminación.

${ }^{57}$ Para Monereo Atienza, Herramientas..., 270 y ss., el problema que tradicionalmente se ha planteado es el de la abstracción en la titularidad de los derechos como factor de descontextualización del ser humano y de consecuente exclusión ideológica de colectivos como la mujer o el extranjero. La universalidad se ha convertido en uno de los temas más conflictivos desde el fenómeno de la globalización. La fragmentación cultural, política y jurídica ha cuestionado el carácter universal de los derechos ya que la contradicción entre su proclamación teórica mayoritaria y su inobservancia práctica es evidente y reconocida unánimemente. 
baremarse disminuyendo el gasto público ${ }^{58}$. La promoción de la igualdad real mediante el recurso a la igualdad formal en los derechos sociales para cumplir sus fines de universalidad genera un coste superior que un trato diferenciado de los sujetos beneficiarios de los mismos y obliga a replantear la universalidad a efectos de justificación económica objetiva, razonable y proporcionada.

La extensión de los derechos sociales al máximo número de destinatarios parece incentivar su eficacia en cumplimiento de la función correctora social e igualadora. Pero la reducción de desigualdades sociales se verifica a través de la igualdad formal entre estos colectivos sin atender a la posibilidad de discriminaciones basadas en un trato igualitario de sujetos desiguales. Por esta razón, en ciertos espacios legales se han normalizado las diferencias como garantía de sujetos en situación de inferioridad jurídica (en el ámbito laboral en beneficio de los trabajadores o de la mujer, entre otros) ${ }^{59}$. Si bien la ausencia de progresividad en la atribución concesional de los derechos sociales puede propiciar tratos igualitarios injustificados entre los beneficiarios, al margen de incrementar el coste económico de las políticas sociales.

El principio de progresividad en el plano de los derechos implica la obligación del Estado de generar una mayor protección y garantía de los derechos, sin embargo, en el derecho tributario determina que los impuestos deben acrecentarse a medida que crece la capacidad contributiva del contribuyente $^{60}$. Ambas vertientes pueden resultar contradictorias si la superior tutela de los derechos sociales se interpreta como una ampliación del ámbito

58 Vid., Monereo Atienza, Herramientas..., 270, esto es así porque la escasez de recursos impide que puedan reconocerse los derechos sociales a todos. Para este autor, la realidad de la escasez no es sólo la base para una concepción económica de la sociedad, ya que si al análisis económico se le añaden ingredientes éticos y políticos la escasez también es un punto de partida para justificar el derecho.

${ }_{59}$ Se ajusta a la Constitución la finalidad tuitiva o compensadora del Derecho laboral en garantía de la promoción de una igualdad real, que en el ámbito de las relaciones laborales exige un minimo de desigualdad formal en beneficio del trabajador. Una vez satisfechas las exigencias de igualdad formal y no discriminación que impone el art. 14 de la Constitución, la propia norma constitucional obliga a atender los requerimientos de la igualdad real, a cuyo fin se ordena el criterio legal de "la capacidad económica del sujeto infractor que aqui se combate, y que resulta así no sólo compatible con el art. 14 de la Constitución sino también justificado o exigido por el art. 31.1 en relación con el art. 9.2 del propio texto constitucional.

${ }^{60}$ Para CARBonell, Eficacia ..., la obligación de progresividad constituye un parámetro para enjuiciar las medidas adoptadas por los poderes legislativo y ejecutivo en relación con los derechos sociales; para Abramovich/Courtis, la noción de «progresividad» y la adopción de medidas «hasta el máximo de los recursos disponibles». La obligación de «progresividad» requiere del Estado una mejora constante en la situación de goce de los derechos sociales. 
subjetivo en el sentido de una mayor universalidad, incluso, aunque exceda de colectivos vulnerables a modo de tarifa plana o café para todos.

Ahora bien, la progresividad desde una perspectiva fiscal puede resultar extrapolable a los derechos sociales considerando que el crecimiento de la capacidad económica incrementa la contribución impositiva con destino a gastos comunes de la sociedad (servicios públicos y sociales). Este principio significa que crece y se grava más la accesibilidad a derechos sociales al aumentar el ingreso bruto o la capacidad económica. Pues la atribución de derechos sociales no puede prescindir del criterio de progresividad fiscal uniformizando a los sujetos y atribuyéndolos con independencia de la capacidad económica. No resulta coherente que mientras a nivel tributario se admita y aplique la progresividad por clases o grupos de renta o por escalones de renta, se configuren derechos sociales ajenos al objetivo de igualdad real. El trato igualitario de los desiguales mediante una aplicación preferente de la universalidad sobre la progresividad, puede contribuir a intensificar las desigualdades, al margen de una discutible asignación de recursos económicos para los derechos sociales y un gasto público superior ${ }^{61}$.

La presunción de legitimidad constitucional en torno a la universalidad de los derechos sociales en los términos configurados por el legislador, impide visibilizar el fenómeno de la discriminación indirecta múltiple, permaneciendo en la actualidad como un reto constitucional de los poderes públicos.

La evaluación de las políticas sociales y de la aplicación de los derechos sociales posibilitaría la apreciación de efectos discriminatorios atendiendo a las quejas de los colectivos vulnerables y sus necesidades. El análisis de los resultados permite la valoración de las desigualdades generadas por la aplicación de la igualdad real a través de la desigualdad normativa ${ }^{62}$.

\subsection{Tendencia individualizadora en los servicios sociales}

La condición intrínsecamente prestacional de los derechos sociales obliga a la adopción de las tendencias evolutivas de los servicios públicos;

${ }^{61}$ Vid. NiKKen, La protección de los derechos humanos..., 22.

62 Entre otros, vid. Monereo Atienza, Herramientas..., así, se debe interpretar la igualdad material como igualdad en los resultados o igualdad en el punto de llegada; Abramovich y Christian Courtis, Apuntes sobre la exigibilidad judicial de los derechos sociales, repositoriocdpd.net:8080/.../Art_CourtisC_ApuntesExibilidadJudicial_2001. pdf?, los derechos sociales, y las de reserva, universalidad y generalidad de ley en la reglamentación de derechos sociales- es necesario desarrollar herramientas de análisis capaces de evaluar la concreción o el incumplimiento de principios fundamentales en materia de derechos sociales: la prohibición de discriminación, el principio de preferencia por los grupos que se encuentran en peor situación, y la prohibición de regresividad o de retroceso social. 
por esta razón, los derechos sociales al servicio de derechos prestacionales no pueden ser ajenos al proceso de individualización iniciado en los servicios públicos ${ }^{63}$.

En esta línea, admite Salazar Pizarro que los derechos sociales son derechos individuales pues pertenecen a la categoría de derecho subjetivo y no pueden ser considerados derechos colectivos. Sin embargo, la universalidad intrínseca a los derechos sociales ha solapado su carácter individual como impedimento para su personalización ${ }^{64}$. La consideración de los beneficiarios de servicios sociales como grupos homogéneos no oculta que en su seno existen necesidades y circunstancias personales y sociales diversas.

Su conversión en derechos de grupo deriva de la universalidad característica de los derechos sociales aunque, en realidad, su causa finalista debe enfocarse a la protección de intereses individuales ${ }^{65}$. Habría que diferenciar entre el acceso a la titularidad de derechos sociales del grupo y la posesión o aplicación de los mismos en el ámbito de los servicios públicos sujetas a las necesidades individuales. En esta línea, la Ley de Cantabria 2/2007, de 27 de marzo, de Derechos y Servicios Sociales (artículo 5), se regula el derecho a acceder al sistema de servicios sociales, sin discriminación por razón de edad, lugar de nacimiento, etnia, sexo, orientación sexual, estado civil, situación familiar, enfermedad, discapacidad física, intelectual o sensorial, religión, ideología, opinión o cualquiera otra circunstancia personal o social; o los Planes de Trabajo Individualizado de alumnado con necesidades especiales de apoyo educativo por discapacidad intelectual).

La tendencia a servicios sociales individualizados a través de políticas públicas debe influir en la individualización de los derechos sociales. La

${ }^{63}$ Vid., PRIETO SANChís, Los derechos sociales..., p. 22, las características que hemos postulado para los derechos sociales, aquí lo que interesa subrayar es su papel al servicio de los derechos prestacionales.

${ }^{64}$ Según Salazar PizArRo, «Fundamentación y estructura de los derechos sociales», Rev. Derecho (Valdivia) vol.26, n. ${ }^{\circ} 1$ (2013), los derechos sociales son derechos individuales, pues los primeros pertenecen a la categoría de derecho subjetivo, siendo esta noción eminentemente individual, por ende, los derechos sociales son derechos individuales. Los Al respecto, los derechos sociales no pueden ser considerados como derechos colectivos, pues el reconocimiento de estos derechos a favor de un colectivo no se debe a la pertenencia de alguien a un determinado grupo de individuos, si fuera lo contrario se estaría atentando a la autonomía del individuo y discriminando a quienes no pertenecen a una colectividad, limitando el carácter universal de los derechos sociales.

${ }^{65}$ Destaca GoRKA MoRENO, «La reformulación del Estado del bienestar: el workfare, las políticas activas de empleo y las rentas mínimas», Revista de Servicios Sociales, n. ${ }^{\circ}$ 43, (2008): 189 y 191; SALAZAR PIZARro, Fundamentación ..., señala Arango que en idéntico sentido argumenta Daniel Riveros, al sostener que los derechos sociales no buscan proteger intereses colectivos, sino que individuales; y que por técnica legislativa se ha clasificado a la población. 
juridificación de derechos sociales individualizados abre la vía a la exigibilidad de su adaptación a las circunstancias personales, familiares y sociales para evitar consecuencias discriminatorias.

La individualización de los servicios sociales se regula como derecho aunque permanece aún reducida a protocolos (Protocolización de la intervención individualizada con mujeres que viven o han vivido violencia de género), o programas, incluso pese a su previsión legal (Ley de Cantabria 2/2007, de 27 de marzo, de Derechos y Servicios Sociales (artículo 5), «derecho...a disponer de un programa individual de atención en los términos que establezca la legislación estatal o autonómica en materia de promoción de la autonomía personal y atención a las personas en situación de dependencia;). El derecho individual a los servicios sociales se presenta como soft law en la actualidad sin un respaldo normativo como refleja la Estrategia Nacional para la Erradicación de la Violencia contra la Mujer 2013-2016, aprobada el 26 de julio de 2013 fijando como uno de los objetivos generales los Planes Personalizados para las víctimas, mientras la Conferencia Sectorial de Igualdad reunida el 17 de junio de 2013, aprobó la puesta en marcha del plan personalizado para las víctimas de violencia de género y los menores a su cargo. Los servicios sociales promueven una brecha en el modelo de derechos sociales limitado actualmente a colectivos estanco (mujeres maltratadas, discapacitados, dependientes...) para progresar hacia una atención personalizada y contextualizada a sus circunstancias personales, familiares o sociales.

Pero estas estrategias, programas o planes individualizados de servicios sociales en el marco de las políticas públicas adolecen de idéntica naturaleza concesional y ausencia de exigibilidad de los derechos sociales, participando del mismo voluntarismo de la Administración y los poderes públicos en su diseño. Sin embargo, a sensu contrario, la desatención a las circunstancias personales, familiares y sociales puede ser un factor discriminatorio que obliga jurídicamente a su consideración en las políticas, derechos y servicios sociales.

Predomina la convicción de que no siendo los derechos sociales vinculantes tampoco pueden serlo los derechos prestacionales derivados ni los servicios sociales, aunque los límites jurídicos operan con plena coercibilidad a pesar de la inexigibilidad característica de aquéllos. En concreto, la igualdad como derecho fundamental no se desactiva por esta naturaleza de los derechos sociales ni por la ausencia de una legislación de desarrollo.

Los servicios sociales personalizados determinan un derecho a la individualización de los derechos sociales que imprime exigibilidad a los mismos a través del derecho fundamental a no ser discriminado por circunstancias familiares, sociales y personales. El derecho a prestaciones sociales a la medida de los destinatarios de derechos sociales, influye en una concepción personalizada de la universalidad. 
Los derechos sociales no pueden, en suma, permanecer indiferentes a la progresiva consolidación de derechos personalizados a prestaciones sociales. La universalidad homogénea de los derechos sociales colisiona con la tendencia a la individualización de su contenido prestacional. Desde una perspectiva antidiscriminatoria y personalizada de los derechos sociales, se refuerza su carácter irreversible y se contiene el riesgo de involución. La desarticulación del sistema de derechos sociales se enfrenta a la desmotivación de las discriminaciones de colectivos vulnerables y además, por sus circunstancias personales, familiares y sociales. La personalización de los derechos sociales contribuye, por consiguiente, a visibilizar la posible arbitrariedad de las políticas sociales de recortes en gasto público ${ }^{66}$. La asistencia individualizada y personalizada es necesaria para la eficacia jurídica de los derechos y servicios sociales sanitarios, educativos, laborales, asistenciales, especialmente en un contexto de crisis económica que exige una distribución certera de los recursos públicos ${ }^{67}$. La universalidad indiferenciada y formal conduce al inmovilismo de los derechos sociales y a las desigualdades o agravios comparativos en el seno de los colectivos vulnerables ${ }^{68}$. La igualdad como límite de los derechos sociales integra lo que puede considerarse el contenido esencial como núcleo irreductible ${ }^{69}$.

${ }^{66}$ Para Bernal Pulido, «Fundamento, concepto y estructura de los derechos sociales Una crítica a “Existen derechos sociales?”» de Fernando Atria, www.cervantesvirtual. $\mathrm{com} / . . . /$ fundamento-concepto-y-estructura-de-los-derechos-soci, esto quiere decir que la legislación de desarrollo de estos derechos es irreversible; que cuando los derechos sociales adquieren un determinado grado de realización, no puede haber una involución que parta de decisiones legislativas. A su vez, a esta prohibición corresponde un derecho individual, exigible ante los tribunales, y que funciona de manera similar a los derechos adquiridos de la doctrina civilista. Los individuos beneficiarios de las prestaciones estatales tienen derecho a seguir disfrutando de ellas, y por tanto, pueden instaurar pretensiones de inconstitucionalidad en contra de las leyes que intenten desarticularlas.

${ }^{67}$ Respecto de la controversia sobre el significado de la igualdad en el artículo 14 de la Constitución Español «la igualdad no es un derecho, puesto que es un modo objetivo de ser la ley prescrito por una norma constitucional», mientras Javier GÁLVEZ, «situar la igualdad como uno más entre los derechos y libertades que se proclaman, sino como uno de los presupuestos necesarios para la efectividad de aquéllos»; Casas Bahamonde, Comentarios a la Constitución, La Ley, 2009, p. 292, sobre la prohibición de discriminar como cláusula abierta.

68 Para Monereo Atienza, «Herramientas...», c Anuario Filosofía del Derecho, (2005): 22, la universalidad no puede ser entendida como universalidad abstracta, sino como universalidad de la diferencia; Liborio Hierro, Los derechos económico-sociales y el principio de igualdad en la teoría de los derechos de Robert Alexy, Biblioteca Virtual Miguel de Cervantes, 2010, p. 256, serían inevitablemente derechos imperfectos bien por su imposible universalidad, bien por su contenido indefinido, bien por su necesariamente imperfecta protección.

69 Según Bernald Pulido, Fundamento, concepto... la libertad de configuración de los derechos sociales, esta libertad debe respetar un mínimo esencial exigido por estos 


\subsection{Evolución democratizadora de los derechos sociales: transparencia y participación}

Por último, la democratización de los derechos sociales proviene a través de la ciudadanización de los servicios públicos locales, basada en los principios administrativos emergentes de información y participación. La transversalidad de los derechos de información y participación diseñan un nuevo modelo de estado de bienestar, con la reconversión de los derechos sociales en derechos de la ciudadanía ${ }^{70}$. En particular, el proceso constructivo de derechos a la información pública y participación aplicables a los servicios públicos, aporta exigibilidad a los derechos sociales. El concepto de usuario de servicios tiende a ser reemplazado por la condición de ciudadano titular de derechos sociales, pues como señala López Camps los ciudadanos no quieren ser receptores pasivos de los servicios públicos y aunque se igualen los conceptos de cliente y ciudadano se pierde el sentido de la responsabilidad ciudadana, reducido a la dimensión de consumidor de servicios y por lo tanto, únicamente le reconocen sus derechos individuales (los derechos de ciudadanía serían prácticamente los derechos del consumidor) renunciando, con ello, a admitir como ciertos los derechos y deberes de ciudadanía, o la defensa del interés general $l^{71}$. En la práctica, el derecho de acceso a la información de los servicios públicos juridifica los derechos sociales y la transparencia pública en su configuración y aplicación y, concretamente el deber legal de publicidad activa se proyecta sobre las políticas, derechos y servicios sociales Así, el Comité de Ética de los Servicios Sociales de Cataluña reconoce el derecho a la información en todos los servicios sociales y a la participación democrática de las personas atendidas o de sus representantes legales en aquellos servicios que así se establezca en la norma que la regule. La atribución de un derecho a recibir información sobre los servicios y las prestaciones públicas, los criterios de adjudicación, las prioridades para recibirlos, los derechos y deberes de las personas usuarias, así como de los mecanismos de presentación de quejas y reclamaciones (artículo 5 Ley de

derechos, que se concreta en: un mínimo de actividad legislativa, la satisfacción del mínimo existencial y el derecho al no retroceso en las prestaciones correspondientes al núcleo esencial de los derechos sociales.

70 Según LóPez CAMPS, La gestión de calidad..., 3 y 7, el sentido desde una nueva lógica política, mucho más atenta a la participación y al desarrollo de la democracia. La crisis del modelo de bienestar también cuestiona el modelo de gobernabilidad practicado en las últimas décadas... Los ciudadanos piden que las administraciones públicas está más atentas y receptivas a las necesidades de los ciudadanos y presten sus servicios con la misma, o mejor calidad, como lo hace el sector privado).

71 Vid., Ganuza Fernández/Gómez ForTes, «Control político y participación en democracia: los presupuestos participativos», Digital CSIC, 2008, p. 14. 
Cantabria 2/2007, de 27 de marzo, de Derechos y Servicios Sociales), implica en consecuencia un «subderecho social» exigible y vinculante.

De otra parte, la participación en los servicios municipales mediante consultas, quejas y sugerencias también refuerza los deberes de los poderes públicos en la esfera de los derechos sociales ${ }^{72}$. Aunque en la actualidad las modalidades participativas en los servicios sociales se basan exclusivamente en instrumentos que permiten sólo conocer la valoración de los ciudadanos sobre el funcionamiento de cualquier servicio municipal (sondeos o estudios de opinión) o el grado de satisfacción de los usuario respecto del funcionamiento de los servicios públicos municipales». No obstante, en última instancia, resulta paradójico que los derechos transversales de información y participación, impriman potencialmente a los derechos sociales un vigor jurídico superior al que presentan por su intrínseca naturaleza.

TITLE: Limits and evolution of social rights Towards its individualization?

RESUMEN: La introspección jurídica en la igualdad como límite de los derechos sociales posibilita el revisionismo del modelo actual y de sus presupuestos en torno a la universalidad y colectivos estanco. La transversalidad de la igualdad contribuye a fundamentalizar los derechos sociales y a reforzar su vinculación jurídica, pero también a visibilizar los efectos discriminatorios de un trato igualitario entre titulares de los mismos. La abstracción de elementos diferenciadores con relevancia jurídica en el diseño de políticas sociales, la inaplicación del principio de progresividad, la ausencia de evaluación de los resultados derivados, fundamentan un control constitucional. La discriminación indirecta, múltiple y por circunstancias personales, familiares o sociales se concitan en el desarrollo práctico de los derechos sociales, cuestionando su constitucionalidad. Como mecanismo antidiscriminatorio y de eficacia, este estudio plantea la posibilidad jurídica de derechos individuales sobre los derechos sociales, con base en la tendencia actual de un derecho personalizado a servicios sociales.

PALABRAS CLAVE: Derechos sociales, igualdad, discriminación, individualización.

ABSTRACT: Legal introspection in equality as the limit of social rights makes possible the revisionism of the current model and its presuppositions

${ }^{72}$ Para LóPEz CAMPS, «La gestión de...», cit., p. 14, la administración debe fomentar la participación activa de los ciudadanos. Estos no quieren ser receptores pasivos de los servicios públicos. Buena parte de la actividad administrativa municipal, por ejemplo, mejoraría sensiblemente si hubiese por un lado una mayor implicación de los usuarios de los servicios y por otra parte una mayor participación de los empleados públicos en la mejora de su prestación. 
around the universality and sealed collective. The mainstreaming of equality contributes to the founding of social rights and to reinforcing their legal linkage, but also to making the discriminatory effects of equal treatment between the rights holders visible. The abstraction of differentiating elements with legal relevance in the design of social policies, the inapplication of the principle of progressivity, the absence of evaluation of the derived results, are based on constitutional control. Indirect discrimination, multiple and by personal, family or social circumstances are aroused in the practical development of social rights, questioning their constitutionality. As an antidiscrimination and efficacy mechanism, this study raises the legal possibility of individual rights over social rights, based on the present tendency of a personalized right to social services.

KEY WORDS: Social rights, equality, discrimination, individualization.

RECIBIDO: 08.04.2017

ACEPTADO: 30.05 .2017 